UDC 37.013 .2

LBC 87.52

\title{
DIGITALIZATION OF EDUCATION DURING THE PANDEMIC PERIOD: SOCIAL CHALLENGES AND RISKS
}

\author{
Natalia N. Pluzhnikova \\ Moscow Technical University of Communications and Informatics, Moscow, Russian Federation
}

\begin{abstract}
The article analyses the digitalization process of education during the pandemic. Thepandemic has accelerated the digitalization process of education and has shown both positive and negative aspects. The key digitalization strategies of education are noted, the specifics of the digitalization model of education are considered. For a more complete consideration of the digitalization process of education, the author uses the analysis of its socio-economic context, represented by the digital economy. The author considers the digitalization of education as the result of a natural process of the digital economy development, where the key factor is not the subject, but digital services. The digital economy is a complex super-system formed by network interactions and feedbacks of its constituent elements. The key characteristic of the development of this super-system is the formal elimination of the subject as an active participant in real economic relations, which leads to alienated forms of human existence. The author examines the manifestation of these alienated forms on the example of distance learning during the pandemic, as well as the impact of information and communication technologies on human thinking and behaviour. The result of this process is a socio-anthropological crisis, which actualizes the social challenges and risks of education digitalization. The author highlights the wide access to educational services, flexibility and high speed of human adaptation to information and communication technologies as positive aspects of the digitalization process of education. The negative side of the digitalization of education is, according to the author, excessive formalization of the educational and training process, which significantly affects the content of educational material, as well as motivational factors for learning and teaching. Based on the results of the study, the author gives forecasts for the future development of the digitalization of education.
\end{abstract}

Key words: education, digitalization, digital economy, pandemic, human.

Citation. Pluzhnikova N.N. Digitalization of Education During the Pandemic Period: Social Challenges and Risks. Logos et Praxis, 2021, vol. 20, no. 1, pp. 15-22. (in Russian). DOI: https://doi.org/10.15688/lp.jvolsu.2021.1.2

УДК 37.013 .2

ББК 87.52

\section{ЦИФРОВИЗАЦИЯ ОБРАЗОВАНИЯ В ПЕРИОД ПАНДЕМИИ: СОЦИАЛЬНЫЕ ВЫЗОВЫ И РИСКИ}

\author{
Наталья Николаевна Плужникова \\ Московский технический университет связи и информатики, г. Москва, Российская Федерация
}

\footnotetext{
Аннотация. В статье проведен анализ процесса цифровизации образования в период пандемии. Пандемия, ускорив процесс цифровизации образования, показала его как положительные, так и отрицательㄱ ные стороны. Отмечены ключевые стратегии цифровизации образования, рассмотрена специфика модеసิ ли цифровизации образования. Для более полного рассмотрения процесса цифровизации образования автор обращается к анализу его социально-экономического контекста, в качестве которого выступает цифровая экономика. Автор рассматривает цифровизацию образования как результат закономерного процесса развития цифровой экономики, в которой ключевым фактором становится не субъект, а цифровые услуги. Цифровая экономика представляет собой сложную суперсистему, образованную сложными сетевыми взаимодействиями и обратными связями составляющих ее элементов. Ключевой характеристикой развития данной суперсистемы является формальная элиминация субъекта как активного участника реальных экономических отношений, что приводит к отчужденным формам существования человека. Автор рассматривает
} 
проявление данных отчужденных форм на примере дистанционного обучения в период пандемии, а также влияния информационно-коммуникативных технологий на мышление и поведение человека. Результатом данного процесса является социально-антропологический кризис, который актуализирует социальные вызовы и риски цифровизации образования. В качестве положительных сторон процесса цифровизации образования автор выделяет широкий доступ к образовательным услугам, гибкость и высокую скорость адаптации человека к информационно-коммуникационным технологиям. Отрицательной стороной процесса цифровизации образования выступает, по мнению автора, излишняя формализация образовательного и учебного процесса, что существенно сказывается на содержании учебного материала, а также на мотивационных факторах к обучению и преподаванию. По результатам проведенного исследования автором даны прогнозы будущего развития процесса цифровизации образования.

Ключевые слова: образование, цифровизация, цифровая экономика, пандемия, человек.

Цитирование. Плужникова Н. Н. Цифровизация образования в период пандемии: социальные вызовы и риски // Logos et Praxis. - 2021. - Т. 20, № 1. - C. 15-22. - DOI: https://doi.org/10.15688/lp.jvolsu.2021.1.2

Одной из ключевых стратегий развития современной системы образования является цифровизация. Цифровизация образования представляет собой перевод образования в «цифру», то есть процесс трансформации образования в глобальную (затрагивающую всех участников) цифровую среду обучения. Данная цифровая среда представляет собой качественно новую образовательно-управленческую структуру, направленную на развитие цифровых технологий и навыков: «Цифровая экономика формирует особый образовательный менеджмент. Управление образованием сегодня - это многовекторный процесс, охватывающий векторы экономического, социального, политического и высокотехнологичного роста. Высокие технологии приобретают весомое значение в цифровом образовании» [Pluzhnikova web]. Цифровизация образования является частью более широкого процесса развития цифровой экономики, которую можно определить как «экономику цифровых товаров и услуг» [Øverby, Audestad 2018, 5].

Для определения специфики современной цифровой модели образования рассмотрим более подробно структуру цифровой экономики, частью которой оно является.

По мнению ряда американских исследователей [Kenney, Zysman 2016, 11], цифровая экономика образована следующими технологическими составляющими:

1) создание больших данных;

2) создание информационно-коммуникационной инфраструктуры, поддерживающей развитие больших данных;

3) цифровая обработка и хранение больших данных.
Развитие информационно-коммуникационных технологий (далее - ИКТ), начиная с середины прошлого века, стало основой развития цифровых технологий в экономике. Существенным фактором в цифровой экономике является то, что она основана на цифровых услугах. Другими словами, под цифровизацию в обществе попадают все, кто производит и потребляет товары и услуги, как и сами эти услуги. Наиболее важными технологиями, которые сформировали цифровую экономику и формируют до сих пор, стали интернет-технологии. Сеть Интернет и сегодня является движущей силой развития цифровой экономики.

Благодаря Интернету стал возможен анализ структурных элементов цифровой экономики, построение моделей ее развития. Построение моделей цифровой экономики проблематично из-за большого количества данных, которые должны быть учтены. Развитая цифровая экономика фокусируется на количественном моделировании цифровых технологий, рынках, оценке стоимости потребления товаров и услуг. Кроме того, отдельные элементы цифровой экономики сложны для анализа сами по себе. Например, цифровые сервисы используют бизнес-модели, описывающие их бизнесоперации. В цифровой экономике существует несколько популярных бизнес-моделей, в том числе бизнес-модели на основе подписки, бесплатной рекламы и многосторонние платформы. Несмотря на то что модели развития цифровой экономики создавать проблематично, попытка их построения и анализа может дать ценную информацию о том, как работает цифровая экономика. 
Н.Н. Плужникова. Цифровизация образования в период пандемии: социальные вызовы и риски

Развитие Интернета позволило выделить основные элементы цифровой экономики. На данный момент основными элементами цифровой экономики выступают цифровые сервисы (различные цифровые платформы по продаже товаров и услуг, в том числе платежные системы), цифровые товары и услуги, провайдеры, дающие доступ к данным услугам, а также потребители этих услуг.

В самом общем виде структура развития цифровой экономики представлена на рисунке.

Данные элементы находятся в постоянной взаимосвязи и образуют сетевую систему с обратными связями и сложными зависимостями. Можно сказать, что в результате взаимодействия данных элементов образуется сложная суперсистема цифровой экономики, которая образована сложными взаимозависимостями и взаимодействием включенных в нее элементов. Поскольку такая система постоянно изменяется, отобразить все зависимости невозможно. Более того, система носит откры- тый характер и оказывает постоянное влияние на жизнедеятельность общества и человека.

Таким образом, модель цифровой экономики представляет собой сложную суперсистему взаимодействия цифровых услуг, инфраструктуры ИКТ и цифровых сервисов, оказывающих влияние на потребителя данной системы - человека. Цифровая экономика как суперсистема состоит из вложенных в нее систем, к которым относятся наука, образование, культура, право, политика и другие сферы общественной жизни человека.

Информационные технологии оказывают активное влияние на все сферы жизни человека, происходит качественная трансформация деятельности человека, в первую очередь, научной и образовательной: «В информационной среде когнитивная структура перестраивается: хабитусы научной и образовательной деятельности трансформируются под влиянием новых, рутинизирующих работу с информационными потоками. В результате увеличивается когнитивный разрыв науки и обра-

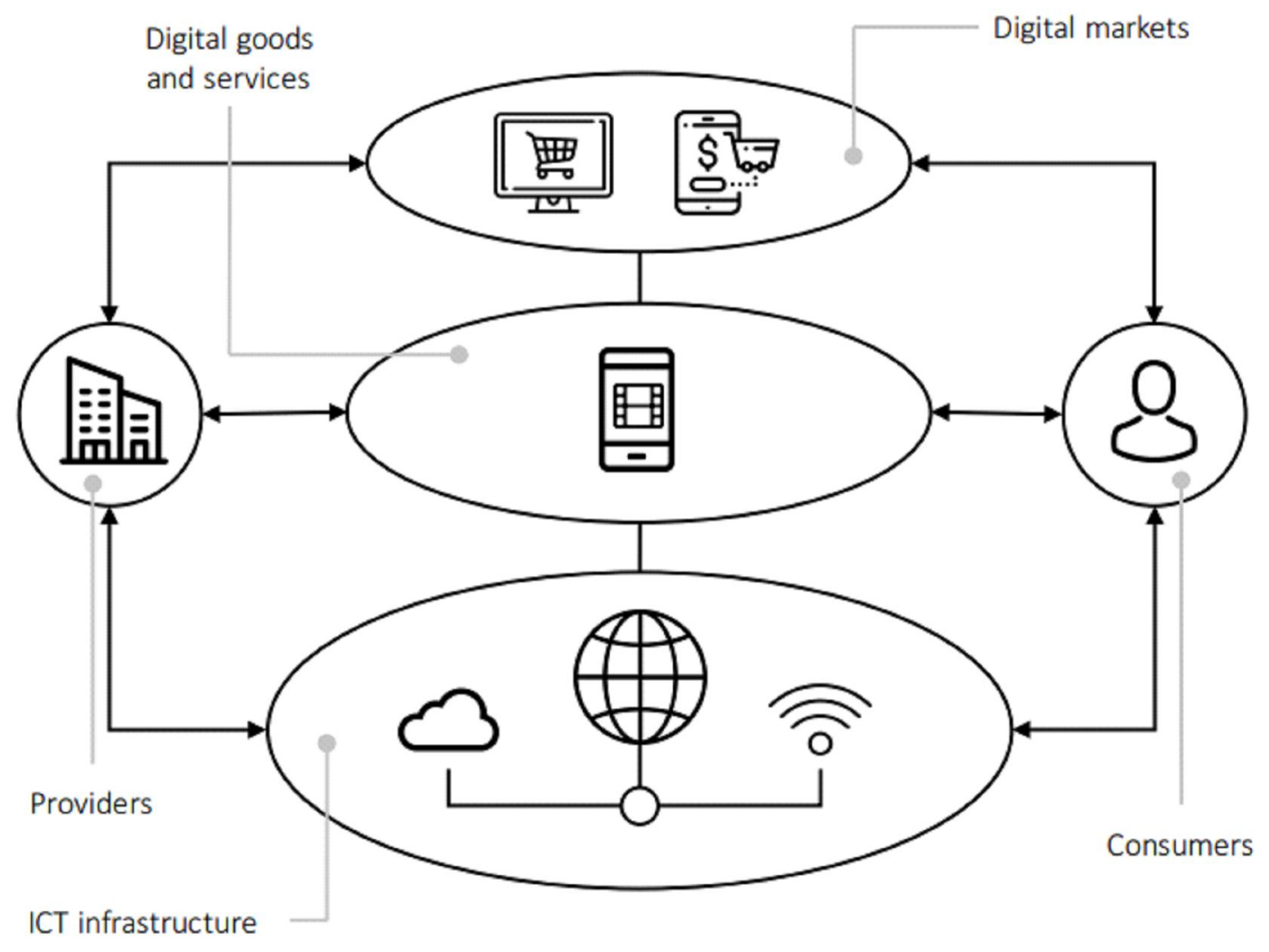

Элементы цифровой экономики

Примечание. Источник: [Øverby, Audestad 2018, 42]. 
зования: научный хабитус, облегчающий интеллектуальные действия, связанные с исследовательской деятельностью и трансляцией научного знания, становится все более специализированным. В этих условиях научное просветительство также нуждается в собственном специализированном хабитусе, обеспечивающем автоматизацию мыслительных операций и интеллектуальных навыков, необходимых для усвоения достижений современной науки в условиях информационной среды» [Токарева, Горина 2017, 27].

Исходя из принятой нами структурной модели образование также выступает цифровой подсистемой цифровой экономики или средой, которая обеспечивает потребителю услуги в области образования. Однако в самой этой модели, если посмотреть на нее более внимательно, потребитель услуг не является центральным звеном. Он является лишь одним из элементов системы. Центральным звеном данной подсистемы становятся цифровые услуги, вокруг которых и создается некая цифровая среда, в которой находится человек. В этих условиях цифровая среда становится автономным носителем отчужденных от потребителя товаров и услуг, а сам человек как реальный субъект потребления и взаимодействия элиминируется. Однако подобная процедура элиминирует субъект лишь номинально. Здесь речь идет не об исключении элемента подсистемы, а всего лишь о перераспределении носителя цифровой системы: «На самом деле считается, что субстанция не исчезает и не появляется, а просто перемещается из одной области в другую либо меняет форму, но, в соответствии с принципом отождествления нетождественного, изменение формы ничего не меняет. Соответственно, в изолированных системах можно измерять параметры не самого процесса, а остальной части системы, то есть измерять одно вместо другого и даже предсказывать поведение тех параметров, которые не измеряются непосредственно. Именно это, в сущности, и позволяет сделать концепция уравнения» [Пигалев 2018, 118].

В такой системе человек как реальный субъект перестает быть активным субъектом не только реального, но и цифрового влияния, поскольку главными становятся цифровые услуги и отношения в сфере оказания циф- ровых услуг. В отношении образования это означает, что главным становится обеспечение образовательного процесса, а не его содержание и субъекты - преподаватели и учащиеся. Формальная сторона процесса образования, а не обучение в системе цифровизации выходит на первый план: формализуется подход к образованию и обучению, который выражается в совершенствовании образовательных технологий, а не содержания учебного процесса и учебного материала.

В России программа цифровизации образования стала активно развиваться в 2016 г., задолго до появления пандемии. Старт данной программы начался с проекта «Цифровая образовательная среда», который был утвержден Проектным комитетом Национального проекта «Образование». Безусловно, пандемия ускорила выполнение проекта по цифровизации образования, как на уровне школ, так и на уровне университетского образования. Результатом этого ускорения стало техническое внедрение и усовершенствование системы дистанционного обучения посредством развития цифровой образовательной среды в вузе. В 2019 г. был запущен Национальный проект «Образование 2019-2024», который направлен на повышение качества и конкурентоспособности российского образования [Национальный проект... web].

Пандемия, ускорив цифровизацию образования, показала быструю адаптацию преподавателей и учащихся к дистанционному обучению, гибкость приобретаемых цифровых навыков и компетенций. Вместе с тем она показала, что немаловажно, психологическую неготовность к данной модели образования как со стороны учащихся, так и со стороны преподавателей; отсутствие мотивационных механизмов к дистанционному обучению в молодежной среде; отсутствие понимания специфики тотальной цифровизации образования со стороны преподавателей.

На фоне пандемии вышеуказанные проблемы проявились особенно отчетливо. Стало совершенно очевидно, что внедрение электронных образовательных ресурсов, разработка онлайн-курсов и цифровых образовательных платформ представляют «формальную упаковку», в основе которой - реальные жизненные задачи и проблемы реальных людей, 
которые обеспечивают образование и обучение, но самой системой из этого процесса элиминируются.

Ярким примером этого процесса является разработка электронной образовательной среды, которая, с одной стороны, открывает различные возможности обучения, делает образование доступным каждому. С другой стороны, использование электронной среды в образовании предполагает жесткую регламентацию множеством формальных требований, например, необходимостью постоянной включенности в данную систему и оставлением так называемых «цифровых следов». Кроме того, техническая сторона процесса дистанционного обучения (поддержание серверов, обеспечение устойчивости беспроводной связи) оказывается более важной составляющей этого процесса, чем содержательная сторона. Технические возможности показали, с одной стороны, готовность перехода образовательных платформ в виртуальное пространство, но, с другой стороны, оказалось, что информационная нагрузка на преподавателей и студентов в условиях быстрой и тотальной цифровизации значительно возросла. Резко увеличился уровень стресса из-за быстрого перехода очного образования в дистанционное и отсутствия механизмов адаптации к новой информационной образовательной среде. Вследствие такой информационной перегрузки «теряется» человек, который продолжает оставаться реальным участником и потребителем цифровых услуг, растворяясь, тем не менее, в потоке тотальной цифровизации.

Тотальная цифровизация не только элиминирует человека, создавая безжизненную цифровую реальность, подчиненную собственной логике развития. Цифровизация формирует такую реальность, которая, игнорируя реальные интересы человека и заменяя их на цифровые потребности, формирует у него качественно иное видение действительности. В этих условиях происходит подмена реальных ценностей и потребностей на виртуальные, что грозит качественной перестройкой мировоззрения личности, оказывает влияние на психологическое состояние и поведение человека. В этих условиях цифровизация становится угрозой для человеческого бытия.
В условиях подобной подмены человек пытается соответствовать формам поведения и социальным правилам, складывающимся в цифровом обществе. Однако в условиях расхождения реального и виртуального, человек не получает должного удовлетворения своих потребностей, не реализует собственные ценности и смыслы. Такая ситуация оборачивается психологической дезадаптацией, потерей мировоззренческих ориентиров и ценностей и может приводить, выражаясь в терминах Э. Фромма и В. Франкла, к коллективным и индивидуальным неврозам.

Результатом тотальной цифровизации становится социально-антропологический кризис, который выражается в неспособности человека не только управлять цифровыми средами, в которых он существует, но и управлять собственными жизненными ценностями и задачами. Более того, эти духовные возможности в тотальной цифровой среде всячески подавляются, уступая место инстинктивным и биологическим потребностям. Таким образом, цифровизация направлена на такую подмену реальности, в которой у человека создается лишь иллюзия знаний, духовности, собственной значимости и уникальности. По своей сути цифровая среда оказывается системой, продуцирующей лишь биологические инстинкты и потребности. Таким образом, сам человек оказывается в условиях замкнутой и детерминистской системы, которая навязывает ему некий искусственный социальный порядок.

Для преодоления социально-антропологического кризиса необходимы, на наш взгляд, следующие базовые принципы, которые должны быть учтены в условиях тотальной цифровизации образования:

1. Ориентированность образования и обучения на базовые духовные ценности и потребности человека, которые станут ответом на детерминистские вызовы цифровой реальности. В качестве форм такого ответа могут выступать творчество, инновационные подходы, способы развития мышления человека. Не случайно сегодня многие эксперты говорят о необходимости развития так называемого «гибкого мышления», приобретения и развития в процессе обучения навыков «Soft skills»: «Социальные навыки нужны больше, чем вы 
думаете!» - таков девиз книги известного сегодня американского программиста и бизнесконсультанта Джона Сонмеза: «Дело в том, что большая часть времени при разработке ПО тратится на взаимодействие с людьми, а не с компьютерами. Даже код мы пишем в первую очередь для человеческого восприятия; понимание его компьютером лишь второстепенная задача. Если бы это было не так, мы бы писали код исключительно на машинном языке - с помощью единиц и нулей. Если хотите быть хорошим разработчиком, то придется научиться эффективно взаимодействовать с людьми (даже если вам больше всего нравится писать код)» [Сонмез 2016, 51].

2. Обучение проблемному мышлению, то есть мышлению, направленному на разрешение проблем и противоречий (знаменитый сократовский метод). Смена бинарного мышления на системное, диалектическое становится необходимым условием эффективного социального взаимодействия и сотрудничества, понимания своих потребностей, а также потребностей другого человека, совместных координат социального взаимодействия.

3. Ответственность как ключевой принцип воспитания человека в процессе образования. Принятие человеком личной ответственности особенно актуально в современном мире: «Для душевного мира человека чрезвычайно важно, чтобы внутри себя он поддерживал то, что делает. Точно так же важно, чтобы он делал то, в пользу чего он решился. Таким образом, он должен поддерживать то, в пользу чего решается. Решиться, действовать и поддерживать - практически это «трилогия стабильности». Если она не соблюдается, возникает внутренний разлад, который опасен психически и физиологически» [Лукас 2020, 202].

Игнорирование данных принципов, на наш взгляд, углубит дальнейшую формализацию процесса образования. На наш взгляд, любая формализация (от наполнения электронной среды информационными ресурсами до размещения на этих ресурсах онлай-лекций без обратной связи со студентами) заранее обречена на провал: «В современном мире необходимо изменить положение общественного мнения и образования. Чрезмерное господство над технологическими и производственными приоритетами создало опасный дисбаланс в образовании, что привело к технократизации общества и не способствовало гуманитарному развитию» [Скляр 2020, 77]. В связи с этим вспомним идею американского ученого М. Полани, который справедливо указывал, что знание всегда имеет личностный характер и не может существовать в полноценном виде, если не передается человеком «из рук в руки» (см.: [Полани 1985]).

Исходя из проведенного нами исследования можно сделать следующие прогнозы развития цифровизации образования:

1. Совершенствование развития и методов внедрения ИКТ в образование приведет к углублению формальной, а не содержательной стороны процесса обучения. Результатом этого может стать снижение мотивации преподавателей не только к образовательной, но и к научно-исследовательской деятельности.

2. Постоянное изменение форм оценки знаний, расширяющееся применение различных измерительных процедур и тестирований для экспертизы качества образовательного процесса отражает приоритет формальной стороны цифровизации процесса образования.

3. Успешное применение информационнокоммуникационных технологий станет главным показателем эффективности образовательной среды и компетентности учащихся и преподавателей. В этих условиях вырастет конкуренция в среде профессорско-преподавательского состава, важными факторами которой станут успешная и быстрая адаптация к информационно-коммуникационным технологиям, а также разработка авторских онлайнкурсов и образовательных ресурсов.

Нетрудно заметить, что данные прогнозы выглядят довольно пессимистично. Однако следует понимать, что формализация образования в условиях цифровой экономики не сможет заменить и исключить личное общение преподавателя и обучающегося. Именно очное образование незаменимо в плане передачи и формирования жизненных ценностей и ориентиров, воспитания человека. Этот аспект, как ни парадоксально, и сделает возможным дальнейшую успешную цифровизацию образования.

Мы убеждены, что дистанционное образование будет иметь ценность для современного человека только тогда, когда оно будет 
Н.Н. Плужникова. Цифровизация образования в период пандемии: социальные вызовы и риски

ориентировано на самого человека. Образование должно быть не тем, что человек получает в качестве услуги, а тем, что он проживает на собственном реальном опыте и тем, как он, исходя из этого опыта, формирует базовые ценности и ориентиры. Только в этом случае реализация проекта цифрового образования будет иметь высокую социальную значимость, повышать мотивацию и качество жизни всех участников образовательного процесса.

\section{СПИСОК ЛИТЕРАТУРЫ}

Лукас 2020 - Лукас Э. Логотерапия и экзистенциальный анализ: Представление о человеке и методы. М.: Когито-центр, 2020.

Национальный проект... web - Национальный проект «Образование 2019-2024»// https:// projectobrazovanie.ru.

Пигалев 2018 - Пигалев А.И. Метафизика как глобальная онтология изолированной системы // Метафизика. 2018. № 3 (29). С. 109-123.

Полани 1985 - Полани М. Личностное знание. На пути к посткритической философии. М.: Прогресс, 1985.

Скляр 2020 - Скляр Л.Н. Гуманистическая модель образования в истории // Цивилизация - общество - человек. Научно-образовательный альманах. Саратов : [б. и.], 2020. С. 76-78.

Сонмез 2016 - Сонмез Дж. Путь программиста. Человек эпохи IT. СПб.: Питер, 2016.

Токарева, Горина 2017 - Токарева С.Б., Горина Т.С. Научно-просветительские практики в условиях информационной технологизации интеллектуальной среды // Logos et Praxis. 2017. T. 16, № 4. C. 23-30.

Kenney, Zysman 2016 - Kenney M., Zysman J. The Rise of the Platform Economy // Issues in Science and Technology. 2016. Vol. 32, № 3. P. 61-69.

Øverby, Audestad 2018-Øverby Hd., Audestad Jan A. Digital Economics How Information and Communication Technology is Shaping Markets, Businesses, and Innovation. N. Y.: [s. n.], 2018.
Pluzhnikova web - Pluzhnikova N.N. Technologies of Artificial Intelligence in Educational Management [Materials of 2020 International Conference on Engineering Management of Communication and Technology, EMCTECH, Vienna, 2020] // https://www.scopus.com/ authid/detail.uri?authorId=56073390700.

\section{REFERENCES}

Lukas E., 2020. Logotherapy and Existential Analysis: The Concept of a Person and Methods. Moscow, Kogito-centr Publ.

National Project «Education 2019-2024». URL: https://projectobrazovanie.ru.

Pigalev A.I., 2018. Metaphysics as a Global Ontology of an Isolated System. Metafizika, no. 3 (29), pp. 109-123.

Polani M., 1985. Personal Knowledge. Towards a PostCritical Philosophy. Moscow, Progress Publ.

Sklyar L.N., 2020. Humanistic Model of Education in History. Civilizaciya-obshchestvo-chelovek. Nauchno-obrazovatel'nyj al'manah. Saratov, pp. 76-78.

Sonmez Dz., 2016. The Programmer's Path. The Man of the IT Era. Saint Petersburg, Piter Publ.

Tokareva S.B., Gorina T.S., 2017. Scientific and Educational Practices in the Context of Information Technologization of the Intellectual Environment. Logos et Praxis, vol. 16, no. 4, pp. 23-30.

Kenney M., Zysman J., 2016. The Rise of the Platform Economy. Issues in Science and Technology, vol. 32, no. 3, pp. 61-69.

Øverby Hd., Audestad Jan A., 2018. Digital Economics How Information and Communication Technology is Shaping Markets, Businesses, and Innovation. New York.

Pluzhnikova N.N. Technologies of Artificial Intelligence in Educational Management. International Conference on Engineering Management of Communication and Technology, EMCTECH 2020 - Proceedings. URL: https://www.scopus.com/authid/ detail.uri?authorId $=56073390700$. 


\section{Information About the Author}

Natalia N. Pluzhnikova, Candidate of Sciences (Philosophy), Associate Professor, Department of Philosophy, History and Intercultural Communications, Moscow Technical University of Communications and Informatics, Aviamotornaya St, 8A, 111024 Moscow, Russian Federation, n.n.pluzhnikova@mtuci.ru, https://orcid.org/0000-0002-4143-1216

\section{Информация об авторе}

Наталья Николаевна Плужникова, кандидат философских наук, доцент кафедры философии, истории и межкультурных коммуникаций, Московский технический университет связи и информатики, ул. Авиамоторная, 8А, 111024 г. Москва, Российская Федерация, n.n.pluzhnikova@mtuci.ru, https://orcid.org/0000-0002-4143-1216 